\title{
Analysis of Canis mitochondrial DNA demonstrates high concordance between the control region and ATPase genes
}

\author{
Linda Y Rutledge ${ }^{1 *}$, Brent R Patterson², Bradley N White ${ }^{3}$
}

\begin{abstract}
Background: Phylogenetic studies of wild Canis species have relied heavily on the mitochondrial DNA control region ( $m t D N A C R$ ) to infer species relationships and evolutionary lineages. Previous analyses of the CR provided evidence for a North American evolved eastern wolf (C. lycaon), that is more closely related to red wolves (C. rufus) and coyotes (C. latrans) than grey wolves (C. lupus). Eastern wolf origins, however, continue to be questioned. Therefore, we analyzed mtDNA from 89 wolves and coyotes across North America and Eurasia at 347 base pairs (bp) of the CR and $1067 \mathrm{bp}$ that included the ATPase6 and ATPase8 genes. Phylogenies and divergence estimates were used to clarify the evolutionary history of eastern wolves, and regional comparisons of nonsynonomous to synonomous substitutions $(d N / d S)$ at the ATPase6 and ATPase8 genes were used to elucidate the potential role of selection in shaping mtDNA geographic distribution.

Results: We found high concordance across analyses between the mtDNA regions studied. Both had a high percentage of variable sites $(C R=14.6 \%$; ATP $=9.7 \%)$ and both phylogenies clustered eastern wolf haplotypes monophyletically within a North American evolved lineage apart from coyotes. Divergence estimates suggest the putative red wolf sequence is more closely related to coyotes $\left(D_{x y} C R=0.01982 \pm 0.00494 S D ; D_{x y} A T P=0.00332 \pm\right.$ $0.00097 \mathrm{SD})$ than the eastern wolf sequences $\left(\mathrm{D}_{x y} C R=0.03047 \pm 0.00664 \mathrm{SD} ; \mathrm{D}_{x y} \mathrm{ATP}=0.00931 \pm 0.00205 \mathrm{SD}\right)$. Neutrality tests on both genes were indicative of the population expansion of coyotes across eastern North America, and $d N / d S$ ratios suggest a possible role for purifying selection in the evolution of North American lineages. $d N / d S$ ratios were higher in European evolved lineages from northern climates compared to North American evolved lineages from temperate regions, but these differences were not statistically significant.

Conclusions: These results demonstrate high concordance between coding and non-coding regions of mtDNA, and provide further evidence that the eastern wolf possessed distinct mtDNA lineages prior to recent coyote introgression. Purifying selection may have influenced North American evolved Canis lineages, but detection of adaptive selection in response to climate is limited by the power of current statistical tests. Increased sampling and development of alternative analytical tools will be necessary to disentangle demographic history from processes of natural selection.
\end{abstract}

\section{Background}

Mitochondrial DNA (mtDNA) has been widely used in phylogenetic studies aimed at answering questions related to ecology and evolution. Its maternal inheritance, lack of recombination, high copy number, variable substitution rates across regions, high mutation rate compared to nuclear DNA, and role in energy

\footnotetext{
* Correspondence: Irutledge@nrdpfc.ca

${ }^{1}$ Environmental and Life Sciences Graduate Program, DNA Building, Trent University, 2140 East Bank Drive, Peterborough, ON, K9J 7B8, Canada
}

production [1] make it an attractive genome for research that aims to understand species relationships, evolutionary history, and demographic patterns within both contemporary and historic contexts. The control region of the mitochondria can be particularly useful in understanding genetic relationships of recently diverged species because it contains hypervariable regions [2]. The high variation can, however, be problematic for inferring phylogenetic relationships due to mutation rate heterogeneity among nucleotide sites [3] and high rates of
C Biomed Central

() 2010 Rutledge et al; licensee BioMed Central Ltd. This is an Open Access article distributed under the terms of the Creative Commons Attribution License (http://creativecommons.org/licenses/by/2.0), which permits unrestricted use, distribution, and reproduction in any medium, provided the original work is properly cited. 
homoplasy $[4,5]$ that can lead to ambiguous phylogeographic patterns [6]. Although not without its own peculiarities [1], coding regions of the mtDNA genome may help clarify genetic and spatial relationships of species inferred from the control region alone. Although all regions of mtDNA are linked and the entire mtDNA genome is inherited as a single molecule without recombination, coding and non-coding sections exhibit different mutation rates due to higher selective forces acting on genes that code for functional proteins [1]. Thus, different patterns of diversity, divergence, and phylogenetic clustering may be evident when comparing regions under divergent selective forces.

In addition to complementing control region phylogenies, analysis of mtDNA coding regions may help resolve geographical distribution patterns because coding regions of the mtDNA are under strong selection due to their fundamental role in energy and heat production $[7,8]$. There is growing evidence that purifying selection on mtDNA coding regions has been important in shaping the evolution and distribution of mtDNA [8-11]. Additionally, adaptive selection may be important [12] with climatic adaptation acting as an influential factor in mtDNA geographic distribution [13-15], although some have disputed the climate hypothesis $[8,16,17]$. Despite this controversy, most agree that the evolution of mtDNA is likely more complex than any single factor could account for. Recent research, however, suggests that the mtDNA ATPase genes in particular, may be influenced by positive selection [8].

To date, studies of North American Canis phylogenetics have relied heavily on the mtDNA control region to infer species relationships and evolutionary history [18-27]. Phylogenetic analysis of the control region provided initial evidence for a North American-evolved wolf, the eastern wolf (Canis lycaon), that shared an evolutionary history with red wolves (C. rufus) and coyotes (C. latrans) independent of grey wolves (C. lupus) that evolved in Eurasia and dispersed into North American approximately 300,000 years ago $[19,20]$. Since then, various research has added to the growing evidence supporting the eastern wolf as a distinct species [28], including genetic analysis of historic [20] and ancient [25] samples. Despite this, the lineage of the eastern wolf continues to be challenged, in part because evidence from coding regions that are under selection is lacking [29]. Indeed, phylogenetic research on wild canids has rarely ventured beyond the mtDNA control region.

Phylogenetic analysis of nuclear Canis markers is complicated by historic and recent hybridization between coyotes, eastern wolves, and gray wolves $[24,25,27]$. The advantage of studying a circular, nonrecombining marker like mtDNA is that patterns of evolutionarily independent lineages can be more easily identified under complicated demographic histories. Here, we use both the control region and the ATPase coding region of the mtDNA genome to infer phylogenetic relationships of the eastern wolf to other Canis species. High levels of hybridization and probable incomplete lineage sorting in eastern North American Canis species $[24,25,27]$ also complicate species inferences from phylogenetic analysis of mtDNA. We, therefore, focus on divergence of phylogenetic clades to provide an understanding of the evolutionary relationships and the role that selection has played in the geographic distribution of Canis mtDNA haplotypes. Our study is the first to provide a substantial analysis of the mtDNA ATPase region in wild Canis populations. For clarity, a list of abbreviations is included at the end of the manuscript.

\section{Results \& Discussion}

\section{Diversity and phylogenetic analysis}

After combining sequences obtained from our study with 9 from Genbank we analyzed 83 control region sequences ( $347 \mathrm{bp} ; \mathrm{h}=29$ ) and 89 ATPase sequences (1067 bp; h = 26) (Table 1). Genbank accession numbers for sequences generated in this study are HM755678-HM755718. Similar to other studies on the control region [18], we found a higher proportion of NW coyote clustering haplotypes per sample size at both the control and ATPase region $(0.38,0.33)$ compared to OW haplotypes $(0.29,0.26)$. (Haplotype assignments to specific samples are shown in Additional File 1: Summary of sample locations and mtDNA control region and ATPase region haplotypes). Overall, we found high concordance between results from the control region and those from the ATPase region despite the different selective forces acting on the two regions. The control region had high variability but only 1.5 times more variable sites and 1.6 times higher nucleotide diversity per site ( $\mathrm{Pi}$ ) compared to the ATPase region (Table 1). Within specific phylogenetic clades, however, Pi was noticeably higher in the control region than the ATPase region (Table 1). The higher diversity in the control region is expected since it is not known to code for functional proteins [30] and has been identified as a mutational hot spot [2]. Recent work, however, suggests that mutational hotspots also occur in coding regions of the mtDNA [31] making the high variation reported here for ATPase genes somewhat less surprising. There were fewer ATPase8 than ATPase6 haplotypes, due to the shorter sequence length of ATPase8, and grey wolves from Sweden, Russian, Spain, and Canada all shared an ATPase8 haplotype (Additional File 1), suggesting that ATPase8 is a highly conserved gene region. 
Table 1 Polymorphism within the mtDNA control region (CR) and ATPase regions

\begin{tabular}{|c|c|c|c|c|c|c|}
\hline Clade & $\begin{array}{c}\text { Number of } \\
\text { sites analyzed }\end{array}$ & $\begin{array}{l}\text { Sample } \\
\text { size }(n)\end{array}$ & $\begin{array}{c}\text { Number of } \\
\text { haplotypes }(\mathrm{h})\end{array}$ & $\begin{array}{c}\text { Number of variable } \\
\text { sites }(\%)\end{array}$ & $\begin{array}{l}\text { Nucleotide diversity } \\
\text { (Pi) per site }\end{array}$ & Pi SD \\
\hline \multicolumn{7}{|c|}{ CR } \\
\hline All ${ }_{C R}$ & 335 & 83 & 29 & $49(14.6)$ & 0.04257 & 0.00214 \\
\hline$N W_{\text {CRall }}$ & 337 & 56 & 20 & $30(8.9)$ & 0.01718 & 0.00223 \\
\hline$N W_{C R 1 e w}$ & 341 & 9 & 2 & $4(1.2)$ & 0.01173 & 0.00587 \\
\hline NW CR2coyl+CR3coyll & 337 & 47 & 18 & $25(7.4)$ & 0.01424 & 0.00161 \\
\hline$N W_{\text {CR2 Coyl }}$ & 338 & 16 & 7 & $15(4.4)$ & 0.0155 & 0.00259 \\
\hline$N W_{C R 3 \text { coyll }}$ & 339 & 31 & 11 & $14(4.1)$ & 0.01019 & 0.0016 \\
\hline OW & 345 & 24 & 7 & $11(3.2)$ & 0.01408 & 0.00176 \\
\hline OW & 345 & 20 & 3 & $2(0.6)$ & 0.00386 & 0.00129 \\
\hline OW & 345 & 4 & 4 & $7(2.0)$ & 0.01208 & 0.00227 \\
\hline \multicolumn{7}{|c|}{ ATPase } \\
\hline All $_{\text {ATP }}$ & 1067 & 89 & 26 & $104(9.7)$ & 0.02596 & 0.00177 \\
\hline NW & 1067 & 61 & 18 & $42(3.9)$ & 0.00543 & 0.00076 \\
\hline NW $W_{\text {ATP1ew }}$ & 1067 & 12 & 2 & $5(0.5)$ & 0.00469 & 0.00234 \\
\hline$N_{\text {ATP2 } 20 y l+A T P 3 c o y l l}$ & 1067 & 49 & 16 & $33(3.1)$ & 0.00441 & 0.00056 \\
\hline NW ATP2coyl & 1067 & 37 & 10 & $16(1.5)$ & 0.003 & 0.00059 \\
\hline $\mathrm{NW}_{\text {ATP3соу\|l}}$ & 1067 & 12 & 6 & $17(1.6)$ & 0.00594 & 0.00073 \\
\hline OW ATPall & 1067 & 27 & 7 & $19(1.8)$ & 0.00643 & 0.00157 \\
\hline OW ATP4gWNA & 1067 & 22 & 2 & $1(0.09)$ & 0.00094 & 0.00047 \\
\hline OW & 1067 & 5 & 5 & $17(1.6)$ & 0.00731 & 0.00164 \\
\hline \multicolumn{7}{|c|}{ ATPase6 } \\
\hline All $_{\text {ATP }}$ & 681 & 89 & 23 & $65(9.5)$ & 0.02513 & 0.00016 \\
\hline NW ATPall & 681 & 61 & 16 & $28(4.1)$ & 0.00592 & 0.00079 \\
\hline NW $W_{\text {ATP1ew }}$ & 681 & 12 & 2 & $5(0.7)$ & 0.00734 & 0.00367 \\
\hline NW ${ }_{\text {ATP2 } 2 \text { coyl+ATP3 } 3 \text { coyll }}$ & 681 & 49 & 14 & $22(3.2)$ & 0.00495 & 0.00064 \\
\hline OW ATPall & 681 & 27 & 7 & $16(2.3)$ & 0.00839 & 0.00133 \\
\hline OW & 681 & 22 & 2 & $1(0.1)$ & 0.00147 & 0.00073 \\
\hline OW & 681 & 5 & 5 & $14(2.1)$ & 0.00881 & 0.00142 \\
\hline \multicolumn{7}{|c|}{ ATPase8 } \\
\hline All $_{\text {ATP }}$ & 204 & 89 & 14 & $23(11.3)$ & 0.03507 & 0.00629 \\
\hline NW & 204 & 61 & 10 & $10(4.9)$ & 0.0111 & 0.00143 \\
\hline OW & 204 & 27 & 4 & $4(2.0)$ & 0.01062 & 0.00311 \\
\hline
\end{tabular}

Analysis was conducted in DnaSP v. 5.10 with nucleotide diversity calculated according to [60]. Gaps were excluded in the analysis. The full 1067 bp of the ATPase region is section 7729 - 8795 in the Canis complete mtDNA genome (Genbank Accession DQ480510) and includes gene regions ATPase8 (204 bp), ATPase6 $(681 \mathrm{bp})$, plus flanking regions that overlap with COX2 and COX3 genes. Subscripts refer to clade designations in Figures $2 \mathrm{a}$ and $2 \mathrm{~b}$. CR $=$ control region; $\mathrm{SD}=$ standard deviation.

There was a wide geographic distribution of NW coyote-like ATPase haplotypes (Figure 1). Cladograms from each genetic region had very similar topologies, which is indicative of the haplotype association of the linked regions. Eastern wolf sequences (Ccr13, Ccr12; Catp13, Catp16) clustered monophyletically with high $(>0.9)$ posterior probability within the NW clade, but apart from coyotes, whereas the putative red wolf sequence clustered among coyote sequences within the $\mathrm{NW}_{\text {CR2 coyI }} / \mathrm{NW}_{\text {ATP2coyI }}$ clade (Figures $2 \mathrm{a}, \mathrm{b}$ ). Similar clustering of the red wolf control region sequence among coyote sequences has been reported [22], but the haplotype is attributed to red wolves because it is not known to occur in non-hybridizing coyotes from western North America. A similar argument has been made for coyote-like eastern wolf haplotypes [27,32]. These geographic distinctions of coyote-like sequences in eastern and red wolves combined with evidence of coyote-like sequences in eastern wolves prior to European settlement in North America [25] provide evidence for incomplete lineage sorting within the NW lineages, although ancient $(\sim 11,000$ years ago) hybridization during the Wisconsin glaciation is difficult to rule out. This, combined with extensive hybridization in eastern Canis populations [23,24,26,27,33,34], makes species designations of wild Canis difficult when based on phylogenetic inference from mtDNA alone. For example, a conspecific nature of eastern wolves and red wolves is 


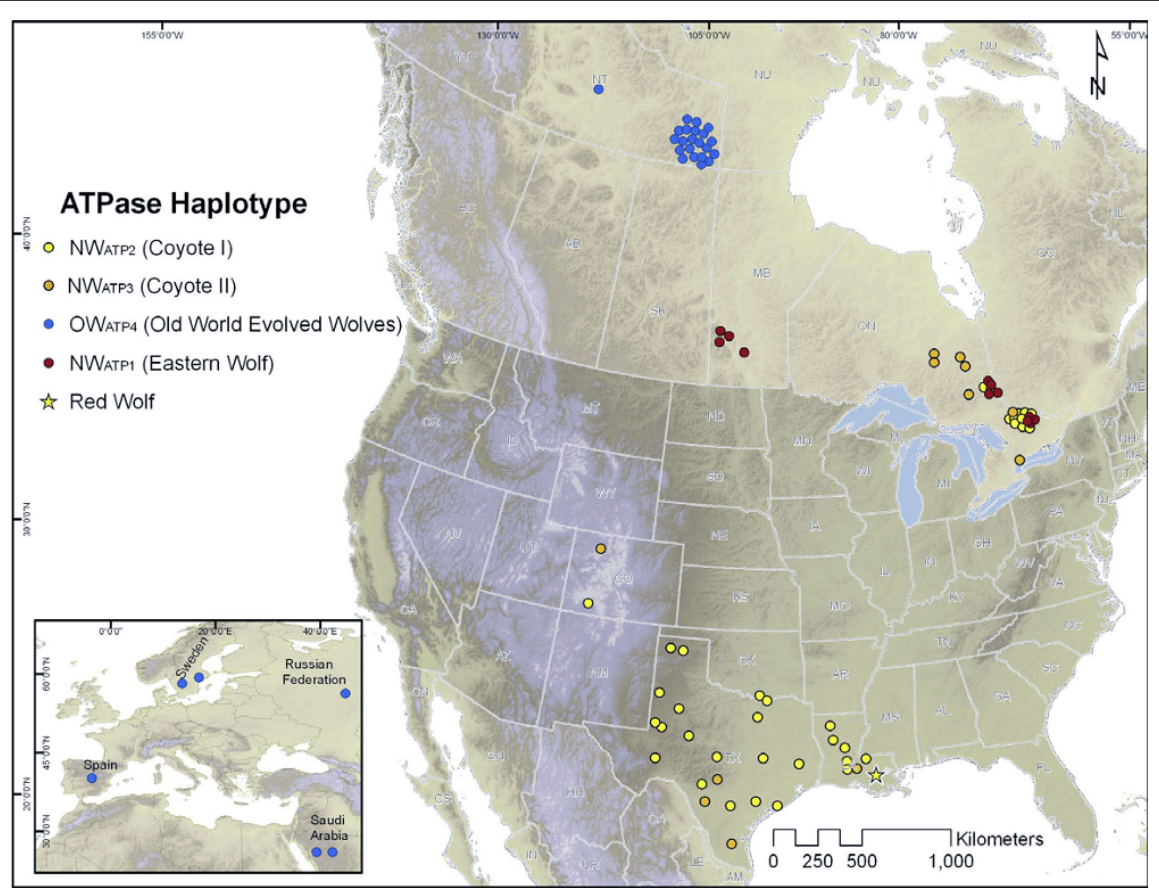

Figure 1 Map of ATPase haplotype distribution. Map of sample locations (circles) showing ATPase haplotype distribution. Colours represent different major clades indicated in Figures $2 \mathrm{a}$ and 2b. Specific locations for Genbank samples from Eurasia, Colorado, and the solitary sample shown in the Northwest Territories were unavailable so a random location within the country or state of origin was chosen.
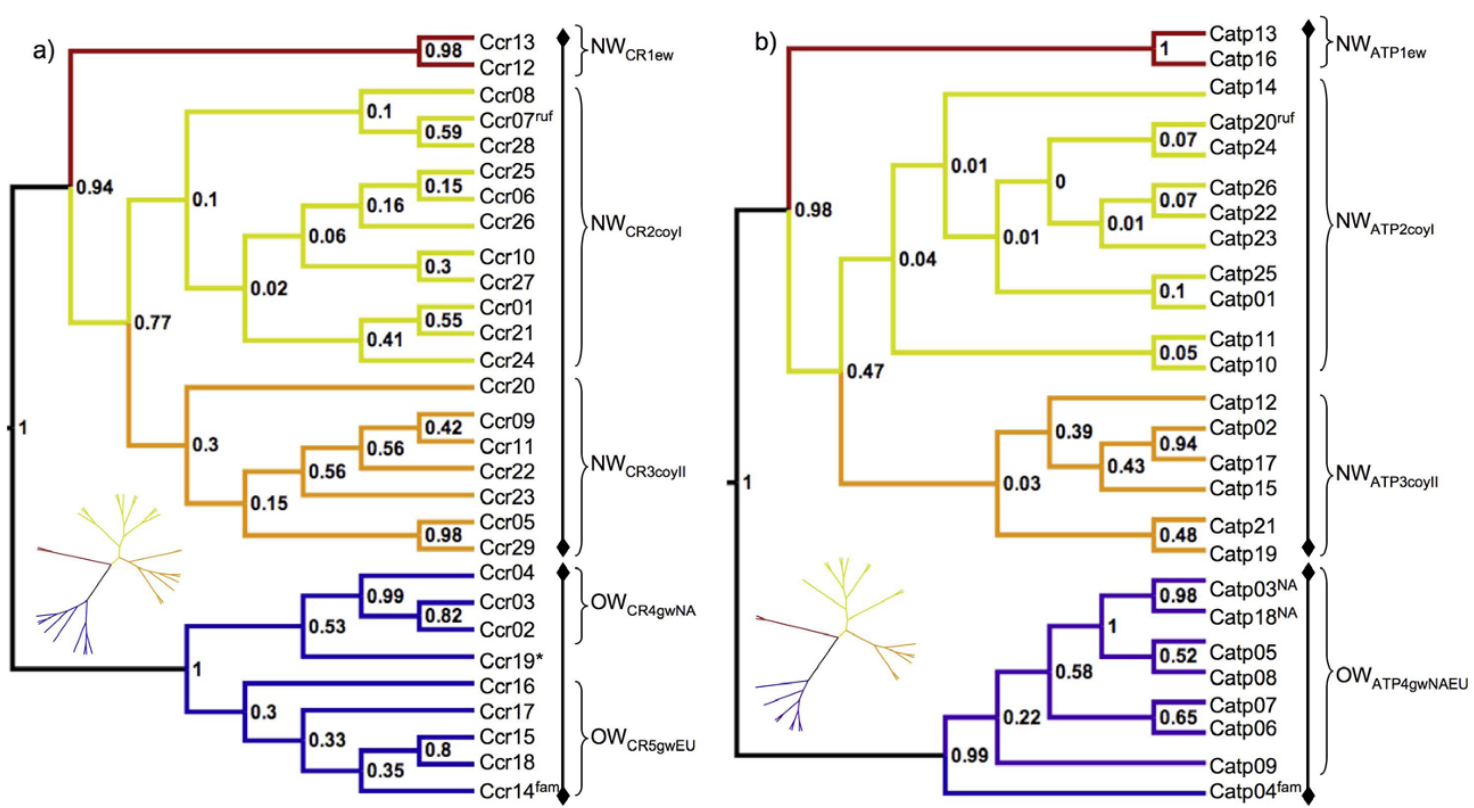

Figure 2 Cladograms of Canis mtDNA CR and ATPase sequences. Cladograms of Canis sequences from Bayesian analysis in BEAST of a) 347 bp of the mitochondrial DNA (mtDNA) control region and b) $1067 \mathrm{bp}$ from the mtDNA ATPase region. ${ }^{\text {fam }}$ is a Husky dog sample from Sweden; * is a wolf from Saudi Arabia; ruf is the red wolf sequence, NW represents New World evolved clades, OW represents Old World evolved clades, $\mathrm{NA}_{\mathrm{A}}$ in b) identifies North American grey wolf samples. Node labels show posterior probabilities rounded to the nearest hundredth. For each genetic region the eastern wolf clade is shown in red (NW $W_{\text {CR1ew }}$ \& NW $\left.N_{\text {ATP1ew }}\right)$, coyote clades I and II are shown in yellow (NW

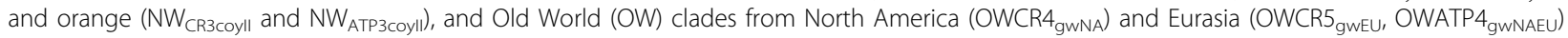
are shown in blue. Insets show radial view of tree. 
suggested by nuclear data [19], but is not demonstrated by analysis of mtDNA. These differences are not unexpected and do not undermine the conspecific nature of eastern wolves and red wolves because gene trees based on mtDNA are not necessarily indicative of specific species relationships, and discordance is often found when comparing mtDNA and nuclear genetic signatures [35]. Given the recent divergence of NW lineages (see below) these issues are not unexpected [35]. New approaches to phylogenetic analysis that utilize multiple loci, including nuclear genes, may help reconcile inferred Canis species relationships [35,36], although extensive hybridization will likely continue to plague contemporary species designations based on nuclear markers. Regardless, the distinction of the two eastern wolf haplotypes shown in both the control region and ATPase region is indisputable, providing clear evidence for the presence of a North American evolved wolf lineage, distinct from coyotes and grey wolves.

\section{Divergence and TMRCA}

Fixed differences occurred in all but one comparison between groups ( $\mathrm{NW}_{\text {ATP2coyI }}$ vs. $\left.\mathrm{NW}_{\text {ATP3coyII }}\right)$ (Table 2). Whereas comparisons of the percentage of nucleotide differences were similar at both mtDNA regions when comparing deep divergences (ie. NW vs. OW), differences were substantially lower for more recent divergence comparisons within NW or OW evolved sequences (Table 2), indicative of possible homoplasy in the hypervariable sections of the control region $[4,5]$. Overall patterns of divergence $\left(D_{\text {xyJC }}\right)$ were similar for the control and ATPase regions, but estimates were consistently lower for ATPase compared to the control region (Figure 3), reflecting the lower observed mutation rate in ATPase.

Based on the control region, divergence of eastern wolves from coyotes was approximately $3.0 \%$, that of the red wolf sequence from coyotes was $2.0 \%$, and eastern wolves compared to red wolves was $2.7 \%$ (Figure 3). These values are consistent with those reported for a 238 bp control region fragment $(3.2 \%, 2.3 \%, 2.1 \%$, respectively) [19]. As expected, divergence estimates from the ATPase region were lower $(0.9 \%, 0.3 \%$, and $0.8 \%$, respectively) but were proportionally consistent with that from the control region. These results complement the phylogenetic analysis and show further confirmation for the eastern wolf lineage. Differences between OW evolved North American and Eurasian wolves were $1.8 \%$ for the control region and $0.6 \%$ at the ATPase region, suggesting a closer relationship between these lineages than between NW lineages.

TMRCA estimates from both genetic regions were similar and suggest divergence of eastern wolf sequences from other North American evolved sequences at approximately 486,300 - 548,400 years ago (ya), and North American grey wolves from Eurasian wolves at 465,600 - 518,100 ya, although the $95 \%$ highest posterior densities (HPD) had wide intervals (Table 3). These values for NW divergence are higher than previous TMRCA estimates of $150,000-300,000$ ya [19] but results are not entirely inconsistent when HPD is considered. Our estimate of NW coalescence is closer to that proposed for coyotes of 420,000 ya in [18], although that study did not identify distinct eastern wolf

Table 2 Nucleotide differences between clades and putative species

\begin{tabular}{|c|c|c|c|}
\hline Comparison (Number of haplotypes) & $\begin{array}{l}\text { Number of sites } \\
\text { compared }\end{array}$ & $\begin{array}{l}\text { Number of fixed } \\
\text { differences }\end{array}$ & $\begin{array}{l}\text { Average number of nucleotide } \\
\text { differences between groups (\%) }\end{array}$ \\
\hline \multicolumn{4}{|c|}{ CR } \\
\hline $\mathrm{NW}_{\text {CRall }}(h=20)$ vs OW $\mathrm{OW}_{\text {CRall }}(h=9)$ & 335 & 14 & $26.6(7.9)$ \\
\hline$N W_{\text {CR1 (ew) }}(h=2)$ vs NW & 337 & 3 & $10.1(3.0)$ \\
\hline $\mathrm{NW}_{\text {CRlew }}(h=2)$ vs RW $(h=1)$ & 341 & 7 & $9(2.6)$ \\
\hline RW $(h=1)$ vs NW & 337 & 2 & $6.6(2.0)$ \\
\hline 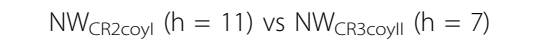 & 337 & 1 & $5.6(1.7)$ \\
\hline $\mathrm{OW}_{\text {CRAgWNA }}(h=3)$ vs OW & 345 & 3 & $6.1(1.8)$ \\
\hline \multicolumn{4}{|c|}{ ATPase } \\
\hline $\operatorname{NW}_{\text {ATPall }}(h=18)$ vs OW ATPall $(h=7)$ & 1067 & 42 & $56.8(5.3)$ \\
\hline $\operatorname{NW}_{\text {ATP1ew }}(h=2)$ vs NW & 1067 & 5 & $9.9(0.09)$ \\
\hline $\operatorname{NW}_{\text {ATPew }}(h=2)$ vs RW $(h=1)$ & 1067 & 6 & $8.5(0.08)$ \\
\hline RW $(h=1)$ vs NW & 1067 & 1 & $3.5(0.03)$ \\
\hline $\operatorname{NW}_{\text {ATP2coyl }}(h=10)$ vs NWATP3coyll $(h=6)$ & 1067 & 0 & $5.4(0.05)$ \\
\hline 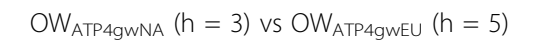 & 1067 & 1 & $6.5(0.06)$ \\
\hline
\end{tabular}

Calculations were done in DnaSP v. 5.10. Gaps were excluded from the analysis. Comparative groups are identified in Figures $2 \mathrm{a}$ and $2 \mathrm{~b}$, and RW is the red wolf sequence identified with superscript "ruf" in Figures 2a and 2b. The dog sequence was excluded from analyses and Ccr19 was excluded from the OW grouping because it clustered independently from North American and Eurasian lineages (see Figure 2a). NW = New World; OW = Old World; CR = control region. 


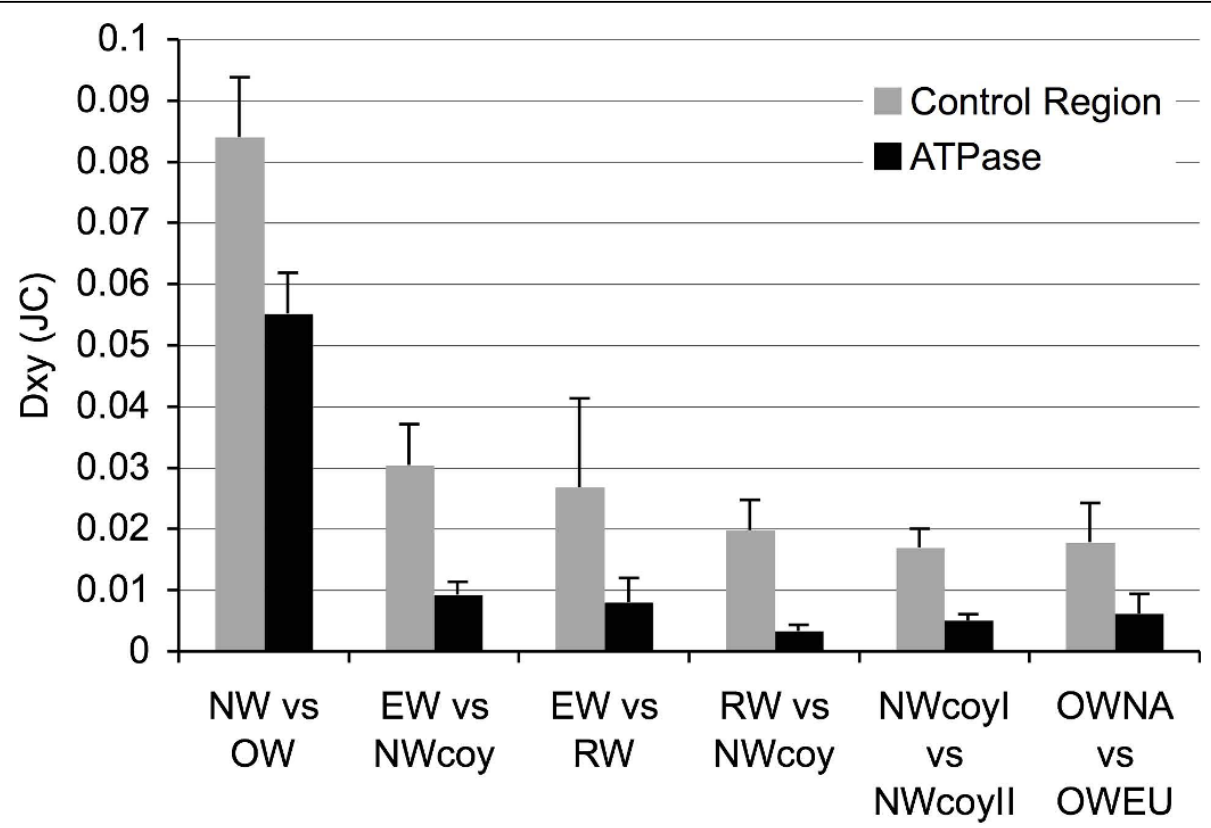

Figure 3 Divergence between populations. Divergence estimates between phylogenetic clades and putative species sequences at the mtDNA control region (347 bp) and ATPase region (1067 bp). Dxy $(J C)=$ average number of nucleotide substitutions per site between populations (with Jukes and Cantor correction). Error bars are the standard deviation. NW = New World evolved sequences; OW = Old World evolved sequences, $\mathrm{EW}=$ eastern wolf sequences; RW = red wolf sequence; NWcoy = NWcoyl + NWcoyll; NWcoyl and NWcoyll represent the two coyote clades shown in Figures 2a and 2b; OWNA = Old World sequences from North America; OWEU = Old World sequences from Eurasia. Gaps were excluded in the analysis.

haplotypes because it occurred prior to identification of eastern wolf sequences [19].

\section{Selection}

Tests of neutrality showed significance in NW lineages, particularly in the ATPase6 region; for ATPase8, only Fu's Fs identified departure from neutrality (Table 4). Over the past 100 years, grey wolves have experienced a genetic bottleneck [37], whereas coyote populations have expanded across North America [23,27], presenting the two extremes of demographic history. Significantly negative values of neutrality statistics can be indicative of selection but are also consistent with either population subdivision or expansion [38], and Fu's Fs is a particularly powerful test of population growth $[39,40]$. Therefore, it is difficult to disentangle selection from demographic history when interpreting neutrality tests $[1,41]$ and care should be taken not to over interpret results from a rejection of the neutrality hypothesis. The known demographic history, however, suggests that results from neutrality tests presented here are indicative of the population expansion of coyotes.

The high rate of synonomous substitutions (SS) in the ATPase genes, particularly in the ATPase6 region where

Table 3 TMRCA estimates

\begin{tabular}{|c|c|c|c|c|c|}
\hline Diverged Lineages & Clades & Mean TMRCA (mya) & SEM & Geometric mean & 95\% HPD \\
\hline \multicolumn{6}{|c|}{ CR } \\
\hline Eastern wolf-Coyote & $N W_{\text {CR1ew }}-N W_{\text {CR2Coyl+CR3coyll }}$ & 0.4863 & 0.0054051 & 0.3302 & $0.00091379-1.224$ \\
\hline NA grey wolf-EU wolf & OW $W_{C R 4 g W N A}-O W_{C R 5 g w E U}$ & 0.5181 & 0.0035853 & 0.3624 & $0.0042139-1.2689$ \\
\hline OW-NW & OW CRall $-N W_{\text {CRall }}$ & 1.3961 & 0.0018707 & 1.3704 & $0.8906-1.9061$ \\
\hline \multicolumn{6}{|c|}{ ATPase } \\
\hline Eastern wolf-Coyote & $N W_{\text {ATP1ew }}-N W_{\text {ATP2Coyl+ATP3coyll }}$ & 0.5484 & 0.0016439 & 0.4889 & $0.139-1.0834$ \\
\hline NA grey wolf-EU wolf & OW $W_{\text {ATP4gWNA }}-O W_{\text {ATP4gWEU }}$ & 0.4656 & 0.0014502 & 0.4124 & $0.1153-0.9494$ \\
\hline OW-NW & $\mathrm{OW}_{\text {ATPall }}-\mathrm{NW}_{\text {ATPall }}$ & 1.8343 & 0.0012901 & 1.8224 & $1.4352-2.2465$ \\
\hline
\end{tabular}

Estimates based on Bayesian analysis of mtDNA control region (CR) and ATPase region in BEAST. Eastern wolf is represented by sample CAN004377 from Algonquin Provincial Park in Ontario, Canada; Coyote is represented by sample CAN000142 from Texas, United States; North American grey wolf is represented by CAN001806 from the Northwest Territories, Canada, Eurasian wolf is represented by a grey wolf from Russia (Genbank Accession DQ480503). Clades are identified in Figures $2 \mathrm{a}$ and $2 \mathrm{~b}$. OW = Old World; NW = New World. 
Table 4 Tests of neutrality within clades and regions

\begin{tabular}{|c|c|c|c|c|c|}
\hline Clade or Region & Sample size & Tajima's $D$ & Fu \& Li $D^{*}$ & Fu $\&$ Li $F^{*}$ & Fu's Fs \\
\hline \multicolumn{6}{|c|}{ ATPase6 } \\
\hline All & 25 & $-0.20630(P>0.10)$ & $-1.05880(P>0.10)$ & $-0.92649(P>0.10)$ & $-6.0687(P<0.05)^{* *}$ \\
\hline NW ATPall & 18 & $-2.23648(P<0.01)^{* *}$ & $-2.90725(P<0.02)^{* *}$ & $-3.14575(P<0.02)^{* *}$ & $-13.0395(P<0.001)^{* *}$ \\
\hline NW ATP2Coyl+ATP3coyll & 16 & $-2.24950(P<0.01)^{* *}$ & $-3.10889(P<0.02)^{* *}$ & $-3.30776(P<0.02)^{* *}$ & $-11.6113(P<0.001)^{* *}$ \\
\hline $\mathrm{NW}_{\text {ATP2coyl }}$ & 10 & $-1.94429(P<0.05)^{* *}$ & $-2.27595(P<0.02)^{* *}$ & $-2.46830(P<0.02)^{* *}$ & $-4.6976(P<0.01)^{* *}$ \\
\hline$N W_{\text {ATPзсоуll }}$ & 6 & $-1.11000 P>0.10)$ & $-1.19719(P>0.10)$ & $-1.27471(P>0.10)$ & $-2.6587(P<0.05)^{* *}$ \\
\hline OW ATPall & 7 & $-0.65997(P>0.10)$ & $-0.71815(P>0.10)$ & $-0.77484(P>0.10)$ & $-1.2687(P>0.10)$ \\
\hline OW ATP4north & 4 & $-0.388921(P>0.10)$ & $-0.38921(P>0.10)$ & $-0.37908(P>0.10)$ & $-0.9463(P>0.10)$ \\
\hline OW ATP4gWEU & 5 & $-0.38168(P>0.10)$ & $-0.38168(P>0.10)$ & $-0.40360(P>0.10)$ & $0.4897(P>0.50)$ \\
\hline \multicolumn{6}{|c|}{ ATPase8 } \\
\hline All & 25 & $0.06944(P>0.10)$ & $-0.42777(P>0.10)$ & $-0.32087(P>0.10)$ & $-1.5442(P>0.20)$ \\
\hline NW ATPall & 18 & $-1.66626(0.10>P>0.05)$ & $-1.79890(P>0.10)$ & $-2.03413(P>0.10)$ & $-6.4462(P<0.001)^{* *}$ \\
\hline NW ATP2Coyl+ATP3coyll & 16 & $-1.63027(0.10>P>0.05)$ & $-1.97065(0.10>P>0.05)$ & $-2.15788(0.10>P>0.05)$ & $-5.5160(P<0.01)^{* *}$ \\
\hline $\mathrm{NW}_{\text {ATP2coyl }}$ & 10 & $-1.74110(P<0.05)^{* *}$ & $-2.01007(0.10>P>0.05)$ & $-2.17902(0.10>P>0.05)$ & $-2.2598(P<0.02)^{* *}$ \\
\hline $\mathrm{NW}_{\text {ATP3 }}$ coyll & 6 & $-0.05722(P>0.10)$ & $0.07132(P>0.10)$ & $0.04654(P>0.10)$ & $-2.4288(P<0.02)^{* *}$ \\
\hline OW & 7 & $-0.65405(P>0.10)$ & $-0.51900(P>0.10)$ & $-0.59207(P>0.10)$ & $0.1098(P>0.40)$ \\
\hline OW ATP $4 \mathrm{gwN}$ North & 4 & $\mathrm{n} / \mathrm{a}$ & $\mathrm{n} / \mathrm{a}$ & $\mathrm{n} / \mathrm{a}$ & $\mathrm{n} / \mathrm{a}$ \\
\hline OW & 5 & $-0.17474(P>0.10)$ & $-0.17474(P>0.10)$ & $-0.17531(P>0.10)$ & $0.0607(P>0.30)$ \\
\hline
\end{tabular}

Sample size is the number of sequences analyzed based on haplotypes determined from the complete ATPase sequence (1067 bp). Dog sequence Catp04 was

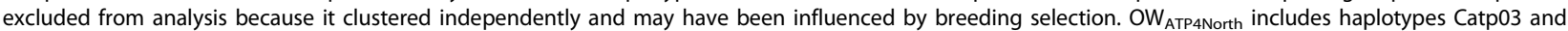
Catp18 from the NWT, Canada, Catp08 from Sweden, and Catp09 from Russia; n/a indicates test not applicable because there were no polymorphic sites. Significantly negative values are indicative of selection, population subdivision or expansion. ${ }^{* *}$ indicates statistical significance.

$d \mathrm{~N} / d \mathrm{~S}$ ratios were all $<0.3$, indicate that purifying selection has been influential in Canis mtDNA evolution, particularly in NW lineages (Table 5). This excess of synonomous substitutions in mtDNA coding regions is consistent with that previously found in wolves, coyotes and dogs [42] and in other mammals including humans $[17,43]$ and mice [11]. This pattern is thought to mainly affect terminal branches of phylogenetic trees suggesting recently diverged groups show a stronger synonomous substitution signal [16], which is consistent with the pattern observed in our dataset.

The ratio of nonsynonomous to synonomous substitutions $(d \mathrm{~N} / d \mathrm{~S})$ was highest for OW lineages from northern climates in the ATPase6 region, but the same pattern was not observed for ATPase8 (Table 5). The difference in $d \mathrm{~N} / d \mathrm{~S}$ ratios between OW and NW lineages is not unusual given that mutations can be neutral in some lineages but non-neutral in others [44]. It has been proposed that amino acid variation in the ATPase genes may reduce the efficiency of oxidative phosphorylation, thereby decreasing ATP production while increasing heat production thus conferring a selective advantage for certain haplotypes in colder climates [13-15], although this hypothesis is not without controversy $[8,16,17]$. The higher $d \mathrm{~N} / d \mathrm{~S}$ ratios for ATPase6 in OW evolved lineages in northern climates compared to NW lineages from more temperate and subtropical climates (Table 5) hints at a possible role for adaptive selection in response to climate for Canis mtDNA
Table 5 Comparison of nonsynonomous (NSS) and synonomous (SS) substitutions in ATPase6 and ATPAse8 genes among clades

\begin{tabular}{|c|c|c|c|c|}
\hline Clade & Sample Size & NSS & SS & $d \mathrm{~N} / d \mathrm{~S}$ \\
\hline \multicolumn{5}{|c|}{ ATPase6 } \\
\hline All & 25 & 11 & 52 & 0.045 \\
\hline $\mathrm{NW}_{\text {ATPall }}$ & 18 & 5 & 23 & 0.073 \\
\hline $\mathrm{NW}_{\text {ATP1ew }}$ & 2 & 1 & 4 & 0.082 \\
\hline $\mathrm{NW}_{\text {ATP2coyl+ATP3coyll }}$ & 16 & 5 & 17 & 0.088 \\
\hline $\mathrm{NW}_{\text {ATP2coyl }}$ & 10 & 2 & 9 & 0.073 \\
\hline $\mathrm{NW}_{\text {ATP3coyll }}$ & 6 & 3 & 8 & 0.112 \\
\hline OW $_{\text {ATP4all }}$ & 7 & 4 & 9 & 0.163 \\
\hline OW & 4 & 3 & 4 & 0.282 \\
\hline \multicolumn{5}{|c|}{ ATPase8 } \\
\hline All & 25 & 10 & 13 & 0.171 \\
\hline $\mathrm{NW}_{\text {ATPall }}$ & 18 & 4 & 6 & 0.295 \\
\hline $\mathrm{NW}_{\text {ATP1ew }}$ & 2 & 0 & 0 & 0.000 \\
\hline $\mathrm{NW}_{\text {ATP2Coyl+ATP3coyll }}$ & 16 & 3 & 6 & 0.214 \\
\hline $\mathrm{NW}_{\text {ATP2coyl }}$ & 10 & 1 & 4 & 0.070 \\
\hline $\mathrm{NW}_{\text {ATP3coyll }}$ & 6 & 2 & 2 & 0.285 \\
\hline OW ATP4all & 7 & 3 & 0 & $\mathrm{n} / \mathrm{a}$ \\
\hline OW ATP4North $_{\text {AT }}$ & 4 & 0 & 0 & 0.000 \\
\hline
\end{tabular}

Sample size is the number of sequences analyzed based on haplotypes determined from the complete ATPase sequence (1067 bp). Dog sequence Catp04 was excluded from the analysis because it clustered independently from other Old World (OW) sequences. OWNorth includes haplotypes Catp03 and Catp18 from the NWT, Canada, Catp08 from Sweden, and Catp09 from Russia. The ratio of nonsynonomous to synonomous substitutions is calculated as $d N / d S$, where $d \mathrm{~N}$ is the number of nonsynonomous substitutions per nonsynonomous site, and $d S$ is the number of synonomous substitutions per synonomous site. All calculations were done in DNAsp v. 5.10. Clades are those identified in Figure $2 \mathrm{~b}$. 
evolution [13], but statistical tests of nonsynonomous and synonomous substitutions did not support adaptive selection in northern regions (Table 6). Although a wolf poisoning campaign in the NWT during the 1950s [45] may have decreased genetic diversity of NWT grey wolves somewhat, it is unlikely to have impacted haplotype diversity to the extent that targeted extermination efforts did in the US [37]. Further complicating interpretation is the recent suggestion that analysis of $d \mathrm{~N} / d \mathrm{~S}$ ratios and the McDonald-Kreitman test are ineffective at detecting positive selection $[46,47]$.

The discrepancies in our analysis and in the human literature does not necessarily mean that climatic adaptation has not influenced the evolution of mtDNA lineages, but suggests rather that mtDNA evolution is more complex than climatic variation alone can explain [8]. Although further investigation on a larger dataset with an alternative approach [15] may help clarify the role of climate in shaping the distribution of Canis mtDNA, and could provide valuable insight into the observed patterns of mtDNA introgression in eastern North American populations, it will remain difficult to separate a signal for adaptive selection from the dramatic and contrasting demographic histories of Canis populations. The development of novel analytical tools will be required to adequately disentangle natural selection from demographic processes.

\section{Conclusions}

Here, we provide important new data for phylogenetic inference of wolves and coyotes in North America. We know of no other study that reports as extensively on the ATPase region in wild Canis species. Similar

Table 6 P values for lineage and climatic comparisons of nonsynonomous and synonomous substitutions

\begin{tabular}{ccc}
\hline Comparison & $\begin{array}{c}\text { Fisher's Exact } \\
\text { Test }\end{array}$ & $\begin{array}{c}\text { McDonald-Kreitman } \\
\text { Test }\end{array}$ \\
\hline & ATPase6 & \\
NW $_{\text {ATPall VS OW }}$ ATP4all & 0.4288 & 0.3017 \\
NW $_{\text {ATPall VS }}$ & 0.3117 & 0.287 \\
OW $_{\text {ATP4North }}$ & ATPase8 & \\
& 0.1923 & 0.4015 \\
NW $_{\text {ATPall VS OW }}$ ATP4all & $\mathrm{n} / \mathrm{a}$ & $\mathrm{n} / \mathrm{a}$ \\
NW $_{\text {ATPall }}$ VS & & \\
OW $_{\text {ATP4North }}$ & &
\end{tabular}

Fisher's exact test is based on raw numbers of nonsynonomous substitutions (NSS) and synonomous substitutions (SS); McDonald-Kreitman test is based on comparisons $d \mathrm{~N} / d \mathrm{~S}$ for fixed differences between populations and polymorphism within a population. $\mathrm{n} / \mathrm{a}$ indicates the test was not applicable because there were no substitutions observed for $\mathrm{OW}_{\text {North }}$ at ATPase8. Dog sequence Catp04 was excluded from analysis because it clustered independently and may have been influenced by breeding selection. $\mathrm{OW}_{\text {North }}$ includes haplotypes Catp03 and Catp18 from the NWT, Canada, Catp08 from Sweden, and Catp09 from Russia. Clades are those identified in Figure 2b. Higher $d \mathrm{~N} / d \mathrm{~S}$ values in samples from more northern climates suggest a selective advantage at colder temperatures. patterns of diversity and divergence between the control region and ATPase regions suggest that evolutionary patterns can be inferred from non-coding regions of mtDNA. Overall phylogenetic concordance between the control and ATPase regions suggests that the control region can be an informative marker for inferring gene trees when dealing with recent divergence. Of particular importance is the monophyletic clustering of eastern wolf sequences under a new Bayesian analytical approach, thereby providing further evidence for a distinct North American evolved wolf, independent of coyotes and grey wolves, that inhabited the temperate forests of eastern North America prior to colonization by European settlers. In addition, eastern wolf sequences are further diverged from coyotes than the red wolf sequence. This does not necessarily imply that the red wolf is not a distinct species but rather supports the assignment of coyote-like sequences as eastern wolf specific.

Understanding the role that selection has had on mtDNA evolution and distribution is a more difficult task. Although the high rate of synonomous substitutions provides evidence that purifying selection may have influenced the evolution of Canis mtDNA, especially in NW lineages, the role of adaptive selection in response to climate is more ambiguous. Adaptive selection may play a role in the geographic distribution of OW mtDNA sequences in North America, but alternative analytical approaches will no doubt be required to adequately test this hypothesis.

Based on the human literature, however, it seems probable that climate is influential in adaptive selection of mtDNA. Further research on adaptive selection of Canis mtDNA is particularly important because it provides a mechanism by which eastern wolf and coyote like mtDNA have introgressed extensively into greyeastern wolf hybrids in northern Ontario and the Great Lakes region $[24,26,27,32,48]$ and why eastern wolf mtDNA is prevalent in eastern coyote populations $[23,27,33,34]$. It is important to note that mtDNA introgression can occur with little or no obvious nuclear introgression [49-51], and in some cases completely replace mtDNA in the absence of apparent nuclear introgression [50,52]. It is possible, therefore, that introgression of NW mtDNA lineages into grey-eastern wolf hybrids in eastern North America, and introgression of eastern wolf mtDNA into eastern coyotes, reflect chance or rare events on which selection then acted creating species discordance between mtDNA and the nuclear genome [1]. Overall, this research provides a new and important framework with which to study patterns of mtDNA introgression and geographic distribution in species where taxonomy has been blurred by incomplete lineage sorting and/or hybridization. 


\section{Methods}

\section{Sequencing}

Previously extracted DNA from 83 individuals from various North American Canis species (eastern wolves, grey wolves, red wolves, and coyotes) were selected to represent a broad spectrum of geographic regions and mtDNA haplotypes. Extraction methods are provided elsewhere [19,53]. Nine additional sequences analyzed in [42] were obtained from GenBank (Accession Numbers: DQ480499, DQ480503 - DQ480508, DQ480510, and DQ480511). Locations for samples used in the present analysis are listed in Additional File 1. All polymerase chain reaction (PCR) amplifications were conducted in a $20 \mu \mathrm{L}$ reaction under the following conditions: approximately 1ng DNA, $1.5 \mathrm{mM} \mathrm{MgCl}_{2}, 0.2 \mathrm{mM}$ dNTPs, $0.2 \mu \mathrm{M}$ forward primer, $0.2 \mu \mathrm{M}$ reverse primer, $0.1 \mu \mathrm{g}$ bovine serum albumin (BSA), $1 \times$ PCR buffer, and 1 Unit of Taq DNA polymerase (Invitrogen, Burlington, Ontario). PCR cycles were run with an initial denaturation at $94^{\circ} \mathrm{C}$ for 5 minutes, followed by 30 cycles of $94^{\circ} \mathrm{C}$ for 30 seconds, $56^{\circ} \mathrm{C}, 58^{\circ} \mathrm{C}$ or $60^{\circ} \mathrm{C}$ (depending on the region being amplified) annealing for 30 seconds, and $72^{\circ} \mathrm{C}$ extension for 30 seconds with a final extension at $72^{\circ} \mathrm{C}$ for 4 minutes. A $\sim 425$ bp fragment of the mtDNA control region was amplified with primers ThrL: 5'-GAA TTC CCC GGT CTT GTA AAC C-3' and DLH-can: 5'-CCT GAG GTA AGA ACC AGA TG$3^{\prime}$ [22] under a $60^{\circ} \mathrm{C}$ annealing temperature. Three primer pairs described in [42] were used to amplify a region that contained the ATPase6 and ATPase8 region of the mtDNA (For7651: 5'-CTT TAT ACC CAT TGT TCT TG-3' and Rev8248: 5'-GGC GTA AAT GAG TGA GGT AAT-3' (597 bp; $56^{\circ} \mathrm{C}$ annealing); For8049: 5'-CCA TTT TAT TCC CAA CAC CC-3' and Rev8501: 5'-GGT AGC CCC TCC ATT CAA A-3' (452 bp; $58^{\circ} \mathrm{C}$ annealing); For8255: 5'-CAA CTC TCT ATA AAC CTC GG-3' and Rev8891: 5'-CGT ATC GTA GTC CTT TTT GTA-3' (636 bp; $58^{\circ} \mathrm{C}$ annealing). We designed additional primer pairs for two of the regions because variation in the primer sites in coyotes led to inefficient amplification. For7651B: 5'-CTT TAT GCC CAT TGT TCT TG-3' and Rev8248B: 5'-GGT GTA AAT GAG TGG GGT AAT-3'; For8049B: 5'-CCA TTT TAT TCC CAG CAC CC-3' and Rev8501B: 5'-GGT AGC CCC TCC AAT CAA G-3'. PCR products were cleaned with ExoSAP-IT (USB Corporation, Ohio) and analyzed on either a MegaBace 1000 (GE Healthcare Bio-Sciences, Baie d'Urfé, Quebec) or an AB 3730 (Applied Biosystems Canada, Streetsville, ON). Contigs from forward and reverse sequences were assembled in Sequencher 4.9 (GeneCodes Corporation, Michigan) and edits were made based on visual inspection of electropherograms. Of the 83 samples, 74 full control region sequences of
347 bp (72 had both forward and reverse, 2 from one direction only) and 80 ATPase region sequences of 1067 bp were generated (base pairs 7729 - 8795 in the Canis mtDNA complete genome sequence DQ480510; Region 1: 70 samples in both forward and reverse directions, 10 in one direction only; Region 2: 77 in both forward and reverse directions, 3 in one direction only; Region 3: 79 in both forward and reverse directions, 1 in one direction only). These, plus the 9 sequences from GENBANK, were used in subsequent analyses. Sequence alignment was done with ClustalW implemented in Geneious 4.5 for Mac OSX (Biomatters Ltd., NZ, http:// www.geneious.com) followed by visual inspection.

\section{Diversity and phylogenetic analysis}

Measures of DNA sequence variation within and among groups, including number of haplotypes $(\mathrm{h})$, variable sites, nucleotide diversity per site $(\mathrm{Pi})$, and average number of nucleotide differences between groups were calculated for the control region, the full ATPase sequence, ATPase6, and ATPase8 in the software program DnaSP v5.10 [54]. Calculations for ATPase6 and ATPase8 were limited to a subset of groups analyzed with the full 1067 bp sequence because the number of variable sites was lower in the specific gene regions, especially in ATPase8, due to the shorter fragment size. Phylogenetic analysis was conducted under a Bayesian framework implemented in the program BEAST v. 1.4.8 [55]. We combined 3 independent runs, each with 10,000,000 MCMC iterations while sampling from the chain every 1000 steps. We used a relaxed uncorrelated lognormal molecular clock [56] with a substitution rate of $3.8 \times 10^{-8} /$ year for the control region $[37,48]$ and $1.5 \times 10^{-9}$ for the ATPase region based on the median rate for substitution at the cytochrome b region in carnivores [57]. Based on Bayesian Information Criteria (BIC) generated in ModelGenerator [58] we used an HKY [59] with invariant sites model with a transition/transversion rate ratio kappa of 45.04 and a 0.79 fraction of invariable sites. As we were interested in putative species phylogenies, we used a Yule tree prior as recommended in the BEAST manual. For the ATPase region, we used an HKY model with a gamma distribution and 4 rate categories, alpha of 0.21 and a transition/transversion rate ratio kappa of 42.96 . To ensure high performance and accuracy, the BEAST output was scrutinized in the software TRACER v. 1.4.1 [60]. Raw traces for all parameters suggested the MCMC had converged on a stationary distribution, and all effective sample size (ESS) values were over 300 (most were over 1000). A burnin of $10 \%$ was used when annotating output files. Maximum clade credibility trees were visualized in FigTree v.1.2.3 http://tree.bio.ed.ac. uk/software/figtree/. 


\section{Divergence and TMRCA}

Divergence between clades was estimated by comparing the number of fixed differences, the average number of nucleotide differences, and the average number of nucleotide substitutions per site with a Jukes and Cantor correction $\left(D_{x y \__{J} C}\right)$ [61] calculated in DnaSP v5.10 [54]. We also compared divergence of the putative red wolf sequence with the eastern wolf clade and other sequences in the broader coyote clade.

Time to most recent common ancestor (TMRCA) was estimated in BEAST software with parameters described above. Four sequences were selected at random to represent the main clades: DQ480503 (Ccr15; Catp09) represented the OW Eurasian lineage, CAN001806 (Ccr03; Catp03) represented the OW North American lineage, CAN004377 (Ccr12; Catp16) represented the eastern wolf lineage, and CAN000142 (Ccr26; Catp22) represented the coyote lineage. Tree calibration was done by setting the divergence distribution between OW and NW lineages based on fossil evidence at 1.5 million years ago and a standard deviation of 0.5 million years such that the $95 \%$ range would be $1-2$ mya $[19,62]$.

\section{Selection}

For all the haplotypes identified in the ATPase phylogenetic tree $(\mathrm{n}=25$, dog excluded) we examined the ATPase6 (681 bp) and ATPase8 (204 bp) regions to test for selection. To test the hypothesis of neutral evolution, we used DnaSP v 5.10 [54] to calculate Tajima's $D$ [63], $\mathrm{Fu}$ and Li's $D^{*}, \mathrm{Fu}$ and Li's $F^{*}$ [64], and Fu's Fs [65] overall and within clades. Significance values for each test are based on the confidence limits of $D$, the critical values of $D^{*}$ and $F^{*}$ [64], or with 1000 replicates in the coalescent simulations approach of DnaSP v. 5.10 for Fu's $F s$. We also tested for neutrality in a group of OW sequences from northern climates (Russia, Sweden, and Northwest Territories, Canada).

To determine whether purifying or adaptive selection influenced the evolution of Canis mtDNA, we compared the number of nonsynonomous substitutions (NSS) to synonomous substitutions (SS), and the ratio of nonsynonomous substitutions per nonsynonomous site to synonomous substitutions per synonomous site $(d \mathrm{~N} / d \mathrm{~S})$ in ATPase6 and ATPase8 overall, within clades, and in the group of OW sequences from northern climates. To test whether climate may have influenced Canis mtDNA distribution, we compared $d \mathrm{~N} / d \mathrm{~S}$ at ATPase 6 and ATPase8 for all NW sequences compared to a) all OW sequences and b) compared to OW sequences from northern climates. If climate were a factor in the adaptive selection of mtDNA, one would expect higher $d \mathrm{~N} / d \mathrm{~S}$ ratios in northern climates compared to more temperate regions [13]. Significance of differences was determined with a two-tailed Fisher's exact test on the raw data (NSS and SS) with the online calculator available at http://faculty.vassar.edu/lowry/VassarStats.html (accessed October 22, 2009) and a McDonald-Kreitman test [66] conducted in DnaSP v. 5.10.

\section{Additional material}

Additional file 1: Sample information and haplotype summary. Canis mtDNA control region and ATPase haplotype summary with comparisons of control region haplotypes found in this study to previously published literature.

\section{Abbreviations}

ATPase: adenosine triphosphatase; Catp: Canis adenosine triphosphatase; Ccr: Canis control region; COX: cytochrome oxidase; coy: coyote (Canis latrans); CR: control region; EU: Eurasia; EW: eastern wolf (Canis lycaon); fam: dog (Canis lupus familiaris); HPD: highest posterior density; mtDNA: mitochondrial DNA; mya: millions of years ago; NA: North America; NW: New World; NWT: Northwest Territories; OW: Old World; ruf: red wolf (Canis rufus); RW: red wolf (Canis rufus); SEM: standard error of the mean; TMRCA: time to most recent common ancestor.

\section{Acknowledgements}

Thanks to Kevin Middel for creating the map figure and to Chris Wilson for providing comments on the manuscript. Also thank you to all the laboratory technicians at the Natural Resources DNA Profiling and Forensic Centre and to previous graduate students who extracted DNA from various samples. Funding from the Ontario Ministry of Natural Resources (OMNR) (BRP) was responsible for sample collection and genetic analyses. A Research Fellowship Award from the OMNR combined with a Natural Sciences and Engineering Research Council (NSERC) doctoral scholarship (LYR) provided funding for genetic analyses and preparation of the manuscript.

\section{Author details}

${ }^{1}$ Environmental and Life Sciences Graduate Program, DNA Building, Trent University, 2140 East Bank Drive, Peterborough, ON, K9J 7B8, Canada. 2Ontario Ministry of Natural Resources, Wildlife Research Development Section, Trent University, DNA Building, 2140 East Bank Drive, Peterborough, ON, K9J 7B8, Canada. ${ }^{3}$ Biology Department, Natural Resources DNA Profiling \& Forensic Centre, DNA Building, Trent University, 2140 East Bank Drive, Peterborough, ON, K9J 7B8, Canada.

\section{Authors' contributions}

LYR conducted all the laboratory work and molecular genetic analyses, and drafted the manuscript. BRP provided samples, was involved in the research study concept, and helped revise the manuscript. BNW guided the laboratory work and molecular genetic analyses, was involved in the research study design, and revised the manuscript. All authors contributed intellectual input as well as read and approved the final manuscript.

Received: 24 February 2010 Accepted: 16 July 2010

Published: 16 July 2010

\section{References}

1. Ballard JWO, Whitlock MC: The incomplete natural history of mitochondria. Mol Ecol 2004, 13:729-744.

2. Stoneking M: Hypervariable sites in the mtDNA control region are mutational hotspots. Am J Hum Genet 2000, 67:1029-1032.

3. Malyarchuk BA, Rogozin IB, Berikov VB, Derenko MV: Analysis of phylogenetically reconstructed mutational spectra in human mitochondrial DNA control region. Hum Genet 2002, 111:46-53.

4. Ingman M, Kaessmann H, Pääbo S, Gyllensten U: Mitochondrial genome variation and the origin of modern humans. Nature 2000, 408:708-713.

5. Avise JC: Molecular Markers, Natural History, and Evolution. Sunderland, Massachusetts, Sinauer Associates, Inc. Publishers 2004. 
6. Torroni A, Achilli A, Macaulay V, Richards M, Bandelt H-J: Harvesting the fruit of the human mtDNA tree. Trends Genet 2006, 22:339-345.

7. Gerber AS, Loggins R, Kumar S, Dowling TE: Does nonneutral evolution shape observed patterns of DNA variation in animal mitochondrial genomes? Annu Rev Genet 2001, 35:539-566.

8. Elson $J$, Turnbull DM, Howell N: Comparative genomics and the evolution of human mitochondrial DNA: assessing the effects of selection. Am J Hum Genet 2004, 74:229-238.

9. Moilanen JS, Majamaa K: Phylogenetic network and physicochemical properties of nonsynonomous mutations in the protein-coding genes of human mitochondrial DNA. Mol Biol Evol 2003, 20:1195-1210.

10. Meiklejohn $C D$, Montooth $\mathrm{KL}$, Rand DM: Positive and negative selection on the mitochondrial genome. Trends Ecol Evol 2007, 23:259-263.

11. Stewart JB, Freyer C, Elson JL, Larsson N-G: Purifying selection of mtDNA and its implications for understanding evolution and mitochondrial disease. Nature Rev Genet 2008, 9:657-662.

12. Doi A, Suzuki H, Matsuura ET: Genetic analysis of temperature-dependent transmission of mitochondrial DNA in Drosophila. Heredity 1999, 82:555-560.

13. Mishmar D, Ruiz-Pesini E, Golik P, Macaulay V, Clark AG, Hosseini S, Brandon M, Easley K, Chen E, Brown MD, Sukernik Rl, Olckers A, Wallace DC: Natural selection shaped regional mtDNA variation in humans. Proc Natl Acad Sci USA 2003, 100:171-176.

14. Ruiz-Pesini E, Mishmar D, Brandon M, Procaccio V, Wallace DC: Effects of purifying and adaptive selection on regional variation in human mtDNA. Science 2004, 303:223-226.

15. Balloux F, Lawson Handley L-J, Jombart T, Liu H, Manica A: Climate shaped the worldwide distribution of human mitochondrial DNA sequence variation. Proc R SOC B 276:3447-3455.

16. Kivisild $T$, Shen $P$, Wall DP, Do $B$, Sung $R$, Davis $K$, Passarino $G$, Underhill PA, Scharfe C, Torroni A, Scozzari R, Modiano D, Coppa A, de Knijff P, Feldman M, Cavalli-Sforza LL, Oefner PJ: The role of selection in the evolution of human mitochondrial genomes. Genetics 2006, 172:373-387.

17. Sun C, Kong Q-P, Zhang Y-P: The role of climate in human mitochondrial DNA evolution: a reappraisal. Genomics 2006, 89:338-342.

18. Vilà C, Amorim IR, Leonard JA, Posada D, Castroviejo J, Petrucci-Fonseca F, Crandall KA, Ellegren H, Wayne RK: Mitochondrial DNA phylogeography and population history of the gray wolf Canis lupus. Mol Ecol 1999, 8:2089-2103.

19. Wilson PJ, Grewal S, Lawford ID, Heal JNM, Granacki AG, Pennock D, Theberge JB, Theberge MT, Voigt DR, Waddell W, Chambers RE, Paquet PC, Goulet G, Cluff D, White BN: DNA profiles of the eastern Canadian wolf and the red wolf provide evidence for a common evolutionary history independent of the gray wolf. Can J Zool 2000, 78:2156-2166.

20. Wilson PJ, Grewal S, McFadden T, Chambers RC, White BN: Mitochondrial DNA extracted from eastern North American wolves killed in the $1800 \mathrm{~s}$ is not of gray wolf origin. Can J Zool 2003, 81:936-940.

21. Adams JR, Kelly BT, Waits LP: Using faecal DNA sampling and GIS to monitor hybridization between red wolves (Canis rufus) and coyotes (Canis latrans). Mol Ecol 2003, 12:2175-2186.

22. Hailer F, Leonard JA: Hybridization among three native North American Canis species in a region of natural sympatry. PLOS ONE 2008, 3:e3333.

23. Kays R, Curtis A, Kirchman JJ: Rapid adaptive evolution of northeastern coyotes via hybridization with wolves. Biol Lett 2009, 6:89-93, doi:10.1098/ rsbl.2009.0575.

24. Koblmüller S, Nord M, Wayne RK, Leonard JA: Origin and status of the Great Lakes wolf. Mol Ecol 2009, 11:2313-2326.

25. Rutledge LY, Bos Kl, Pearce RJ, White BN: Genetic and morphometric analysis of sixteenth century Canis skull fragments: implications for historic eastern and gray wolf distribution in North America. Conserv Genet 2009, 11:1273-1281.

26. Wheeldon T, White BN: Genetic analysis of historic western Great Lakes region wolf samples reveals early Canis lupus/lycaon hybridization. Biol Lett 2009, 5:101-104.

27. Wilson PJ, Grewal SK, Mallory FF, White BN: Genetic characterization of hybrid wolves across Ontario. J Hered 2009, 100(Supplement 1):S80-S89.

28. Kyle CJ, Johnson AR, Patterson BR, Wilson PJ, Shami K, Grewal SK, White BN: Genetic nature of eastern wolves: past, present and future. Conserv Genet 2006, 7:273-287.
29. Murray $D L$, Waits LP: Taxonomic status and conservation strategy of the endangered red wolf: a response to Kyle et al. (2006). Conserv Genet 2007, 8:1483-1485.

30. Pakendorf B, Stoneking M: Mitochondrial DNA and human evolution. Annu Rev Genomics Hum Genet 2005, 6:165-183.

31. Galtier N, Enard D, Radondy Y, Bazin E, Belkhir K: Mutation hot spots in mammalian mitochondrial DNA. Genome Res 2006, 16:215-222.

32. Rutledge LY, Garroway CJ, Loveless KM, Patterson BR: Genetic differentiation of eastern wolves in Algonquin Park despite bridging gene flow between coyotes and grey wolves. Heredity 2010.

33. Way J, Rutledge LY, Wheeldon T, White BN: Genetic characterization of northeastern coyotes in eastern Massachusetts. Northeast Nat 2010, 17:189-204.

34. Wheeldon TJ, Patterson BR, White BN: Colonization history and ancestry of northeastern coyotes. Biol Lett 2010, 6:246-247.

35. Degnan JH, Rosenberg HA: Gene tree discordance, phylogenetic inference and the multispecies coalescent. Trends Ecol Evol 2009, 24:332-340.

36. Springer MS, DeBry RW, Douady C, Amrine HM, Madsen O, de Jong WW, Stanhope MJ: Mitochondrial versus nuclear gene sequences in deeplevel mammalian phylogeny reconstruction. Mol Biol Evol 2001, 18:132-143.

37. Leonard JA, Vilà C, Wayne RK: Legacy lost: genetic variability and population size of extirpated US gray wolves (Canis lupus). Mol Ecol 2005, 14:9-17.

38. Ray N, Currat M, Excoffier L: Intra-deme molecular diversity in spatially expanding populations. Mol Biol Evol 2003, 20:76-86.

39. Fu Y-X: Statistical tests of neutrality of mutations against population growth, hitchhiking and background selection. Genetics 1997, 147:915-925.

40. Ramos-Onsins SE, Rozas J: Statistical properties of new neutrality tests against population growth. Mol Biol Evol 2002, 19:2092-2100

41. Hedrick PW: Genetics of Populations. Sudbury, Massachusetts, Jones and Bartlett Publishers 2000.

42. Björnerfeldt $S$, Webster MT, Vilà C: Relaxation of selective constraint on dog mitochondrial DNA following domestication. Genome Res 2006, 16:990-994.

43. Howell N, Elson JL, Howell C, Turnbull DM: Relative rates of evolution in the coding and control regions of African mtDNAs. Mol Biol Evol 2007, 24:2213-2221.

44. Moilanen JS, Finnilä S, Majamaa K: Lineage-specific selection in human mtDNA: lack of polymorphisms in a segment of MTND5 gene in haplogroup J. Mol Biol Evol 2003, 20:2132-2142.

45. Heard G, Angell J: Historical and present status of wolves in the Northwest Territories. Wolves in Canada and Alaska Canadian Wildlife Service Report Series, No. 45, Canadian Wildlife Service, Ottawa, Ontario, CanadaCarbyn LN 1983, 44-47.

46. Kryazhimskiy S, Plotkin JB: The population genetics of $d \mathrm{~N} / d \mathrm{~S}$. PLoS Genet 2008, 4:e10000304, (doi: 10.1371/journal.pgen.10000304).

47. Zhai W, Nielsen R, Slatkin M: An investigation of the statistical power of neutrality tests based on comparative and population genetic data. Mol Biol Evol 2009, 26:273-283.

48. Leonard JA, Wayne RK: Native Great Lakes wolves were not restored. Biol Lett 2008, 4:95-98.

49. Powell JR: Interspecific cytoplasmic gene flow in the absence of nuclear gene flow: evidence from Drosophila. Proc Natl Acad Sci USA 1983, 80:492-495.

50. Bernatchez L, Glemet H, Wilson CC, Danzmann RG: Introgression and fixation of Arctic char (Salvelinus alpinus) mitochondrial genome in an allopatric population of brook trout (Salvelinus fontinalis). Can J Fish Aquat Sci 1995, 52:179-185.

51. Sota T: Radiation and reticulation: extensive introgressive hybridization in the carabid beetles Ohomopterus inferred from mitochondrial gene genealogy. Popul Ecol 2002, 44:145-156.

52. Nevado B, Koblmüller S, Sturmbauer C, Snoeks J, Usano-Alemany J, Verheyen E: Complete mitochondrial DNA replacement in a Lake Tanganyika cichlid fish. Mol Ecol 2009, 18:4240-4255.

53. Rutledge LY, Patterson BR, Mills KJ, Loveless KM, Murray DL, White BN: Protection from harvesting restores the natural social structure of eastern wolf packs. Biol Conserv 2010, 143:332-339. 
54. Librado P, Rozas J: DnaSP v5: a software for comprehensive analysis of DNA polymorphism data. Bioinformatics 2009, 25:1451-1452.

55. Drummond AJ, Rambaut A: BEAST: Bayesian evolutionary analysis by sampling trees. BMC Evol Biol 2007, 7:214.

56. Drummond AJ, Ho SYW, Phillips MJ, Rambaut A: Relaxed phylogenetics and dating with confidence. PLoS Biol 4:e88.

57. Nabholz B, Glémin S, Galtier N: Strong variations of mitochondrial mutation rate across mammals - the longevity hypothesis. Mol Biol Evol 2007, 25:120-130.

58. Keane TM, Creevey CJ, Pentony MM, Naughton TJ, Mclnerney JO: Assessment of methods for amino acid matrix selection and their use on empirical data shows that ad hoc assumptions for choice of matrix are not justified. BMC Evol Biol 2006, 6:29.

59. Hasegawa M, Kishino H, Yano TA: Dating of the human-ape splitting by a molecular clock of mitochondrial DNA. J Mol Evol 1985, 22:160-174.

60. Rambaut A, Drummond AJ: Tracer v1.4. 2007 [http://beast.bio.ed.ac.uk/ Tracer].

61. Nei M: Molecular Evolutionary Genetics. New York, Columbia University Press 1987.

62. Kurtén B, Anderson E: Pleistocene mammals of North America. New York, Columbia University Press 1980

63. Tajima F: Statistical method for testing the neutral mutation hypothesis by DNA polymorphism. Genetics 1989, 123:585-595.

64. Fu YX, Li WH: Statistical tests of neutrality of mutations. Genetics 1993, 133:693-709.

65. Fu YX: Statistical tests of neutrality of mutations against population growth, hitchhiking and background selection. Genetics 147:915-925.

66. McDonald JH, Kreitman M: Adaptive protein evolution at the Adh locus in Drosophila. Nature 1991, 351:652-654.

doi:10.1186/1471-2148-10-215

Cite this article as: Rutledge et al: Analysis of Canis mitochondrial DNA demonstrates high concordance between the control region and ATPase genes. BMC Evolutionary Biology 2010 10:215.

\section{Submit your next manuscript to BioMed Central and take full advantage of:}

- Convenient online submission

- Thorough peer review

- No space constraints or color figure charges

- Immediate publication on acceptance

- Inclusion in PubMed, CAS, Scopus and Google Scholar

- Research which is freely available for redistribution

Submit your manuscript at www.biomedcentral.com/submit
Ciomed Central 